\title{
Criterios \\ Principales características de los hongos causantes de alteraciones en materiales celulósicos
}

\author{
M. Ángeles Calvo Torras' > Carles Adelantado" > Esther Corcuera Marín"'
}

\section{Resumen}

El deterioro de los libros a causa de los hongos es un grave problema al que debe enfrentarse el conservador-restaurador. Las degradaciones causadas por hongos en las bibliotecas y archivos podrian evitarse aplicando un plan de prevención que contemplase un mejoramiento de las condiciones ambientales así como de los emplazamientos de archivos y bibliotecas.

Asimismo la aplicación de unas medidas higiénicas de limpieza en los archivos y bibliotecas ayudarian sin duda a evitar futuras infecciones. Cuando ya se ha producido una infección, los tratamientos con biocidas pueden erradicar el problema, aunque su alto coste y toxicidad no los convierten en el procediento más adecuado. Para evitar estos inconvenientes, resulta mucho más eficaz practicar medidas preventivas de forma sistemática, elaborar planes de actuación previos a la contaminación y aplicar los conocimientos del conservador-restaurador sobre los hongos y sus métodos de eliminación.

\section{Palabras clave}

\section{Factores de alteración}

Prevención

Microorganismos

Hongos

Infección

Papel

Celulosa

Condiciones medioambientales

Agentes de biodeterioro

\section{Introducción}

Una de las causas de degradación e incluso destrucción de libros en bibliotecas y archivos es la acción de los agentes bióticos, entendiendo como a tales a los microorganismos (hongos filamentosos, levaduras y bacterias), insectos y roedores. En este artículo de revisión, analizaremos las características diferenciales de los hongos y nos centraremos en la acción destructora de los hongos bibliófagos, causantes frecuentes de alteraciones en las bibliotecas y archivos.

\section{Hongos}

Los hongos son seres eucariotas que pueden ser pluricelulares (hongos miceliares) o unicelulares (levaduras). Por sus características diferenciales, constituyen actualmente el denominado quinto reino de la naturaleza. Se desarrollan fácilmente en una gran variedad de sustratos, siendo factores fundamentales para su desarrollo las condiciones de humedad y temperatura.

En el concepto de hongos microscópicos se incluyen las levaduras y los hongos miceliares o mohos. Bajo el punto de vista taxonómico se han descrito un total de 2.500 géneros que incluyen del orden de unas 65.000 especies y de ellas son las de los hongos miceliares las que tienen más interés por su capacidad de degradar sustratos celulósicos.

\section{Estructura}

El desarrollo de los hongos miceliares determina la formación del denominado talo en el que podremos distinguir dos tipos de estructuras: vegetativa y reproductora.

$>$ Vegetativa. Al observar la estructura vegetativa de los hongos filamentosos podemos diferenciar las hifas, cada uno de los filamentos en forma de tubos finos y largos que entrelazados forman el micelio; poseen una pared delgada y transparente y pueden diferenciarse según poseen o no septos transversales. El micelio es el conjunto de hifas que constituye el talo de un hongo.

$>$ Reproductora. Cuando ya se ha formado el micelio, los hongos filamentosos se reproducen mediante la formación de esporas asexuales o conidios que se encuentran y que se originan a partir de células diferenciadas de las hifas. Los hongos miceliares pueden multiplicarse mediante un proceso de reproducción asexual o bien por un proceso de reproducción sexual. Si el proceso de reproducción es asexual, es el conidio o espora asexual que, una vez madura, se desprende y, en condiciones de sustrato correctas, germina dando lugar a un nuevo hongo miceliar. Si el proceso de reproducción es sexual, es preciso que dos células de signo complementario se recombinen y originen las esporas sexuales capaces, en condiciones medio-ambientales propicias, de formar nuevas colonias fúngicas. 
I Catedrática de Sanitat Animal de la Universitat Autònoma de Barcelona

" Investigador

III Restauradora
Los conidios o esporas asexuales se forman a partir de estructuras diferenciadas presentes en el micelio. Cuando germinan, originan microorganismos genéticamente iguales al inicial. Los conidios pueden ser solitarios o formar cadenas al final de un conidióforo. Existen varios tipos de conidios, como por ejemplo la conidiospora, originada en especies de los géneros Penicillium, Aspergillus, Cladosporium, Fusarium, Alternaria y Trichoderma, entre otros, o la esporangiospora, producida por especies de los géneros Rhizopus, Mucor, Absidia, entre otros. En este caso, los conidios se originan en el interior y a partir del esporangio, al final de una hifa aérea denominada esporangióforo.

Las esporas sexuales son el producto final de la recombimación de dos cepas de signo complementario pertenecientes a la misma especie de hongos. Los organismos originados a partir de esporas sexuales tienen características genéticas de las dos cepas iniciales. Existen varios tipos de esporas sexuales, como por ejemplo: ascosporas, basidiosporas y zigosporas.

\section{Alimentación}

Los hongos no poseen clorofila y por tanto no pueden realizar la fotosintesis. Para mitigar esta falta, los hongos obtienen los carbohidratos de materia orgánica, como por ejemplo del papel. Son heterótrofos. Es decir, se alimentan de materia orgánica, como por ejemplo la celulosa del papel, y por eso son frecuentes en archivos y bibliotecas. Los hongos necesitan de ciertos elementos para su desarrollo, como son el carbono, el nitrógeno, el oxigeno, el nitrógeno, el azufre, el potasio y el magnesio. También pueden necesitar oligoelementos como el zinc, el hierro, el manganeso, el cobre y a veces el calcio y algunas vitaminas.

La composición de los distintos materiales que se encuentran en bibliotecas y archivos los convierten en un substrato adecuado para su desarrollo. Además los libros son un aporte nutritivo muy importante para los hongos, puesto que están constituidos de muchas sustancias diferentes: fibra celulósica, caseína, adhesivos naturales, almidón, gelatina, colas, dextrinas, aminoácidos, sales metálicas y otras impurezas. El polvo y la tierra también proporcionan nutrientes suplementarios que precisan los hongos para su adecuado desarrollo.

\section{Desarrollo}

Los hongos son estructuras pluricelulares que necesitan, en general, de un medio ácido ( $\mathrm{pH}$ 4.5-5) para formar sus colonias. Crecen en condiciones de humedad y temperatura que como término medio podríamos cifrar en $25-28^{\circ} \mathrm{C}$ y $65-70 \%$ de HR (humedad relativa). No obstante, algunas especies pueden desarrollarse en condiciones extremas. También puede favorecer el desarrollo de estos microorganismos una acumulación de polvo provocada, por ejemplo, por una mala ventilación.

Los conidios poseen estructuras muy resistentes y toleran condiciones ambientales muy desfavorables. Pueden quedar en estado latente durante un tiempo indefinido hasta que las condiciones ambientales sean las adecuadas para su subsistencia (humedad y temperatura adecuadas, nutrientes, etc.).

\section{Propagación}

La propagación de los hongos se realiza por medio de los conidios o esporas asexuales y por las esporas sexuales. Estas estructuras son fáciles de trasladar por el aire (al limpiar el polvo por ejemplo), a través de los zapatos y las ropas de las personas que se encuentran en contacto con ellas, o a través de sistemas de climatización.

\section{Causas de infección de libros y documentos de archivos}

Cuando se produce una infección por hongos en un archivo o en una biblioteca, la causa principal de la contaminación es difícil de establecer, como consecuencia de la variedad de causas que pueden provocar una infección y que pueden ser divididas en dos clases, primarias y secundarias (LIÉNARDY, A; VAN DAMME, P., 1989:80-81), dependiendo de su origen.

Se denomina infección primaria a la contaminación producida por hongos en el papel en el momento de la fabricación de la pasta. En este proceso se añaden diversos tipos de materiales, como vegetales, trapos, papeles viejos, adhesivos, maderas o colas. Este tipo de sustancias pueden estar infectadas por conidios, y provocar una contaminación del soporte celulósico. Los microorganismos poseen una gran capacidad de adaptación al medio, pudiéndose quedar en estado latente dentro del papel, hasta que las condiciones medioambientales (humedad relativa y temperatura altas) sean las más óptimas para su desarrollo.

Cuando la infección por hongos se produce posteriormente a la fabricación del papel, se la denomina infección secundaria y las causas de esta contaminación fúngica pueden ser varias:

$>$ El uso y manipulación de los libros en las bibliotecas y archivos provocan ciertas alteraciones, a veces de carácter irreversible en el soporte celulósico. A causa de esta manipulación por parte del hombre, los hongos pueden desarrollarse sobre sustancias orgánicas como la saliva y la grasa, existentes en dosis pequeñas en el papel y en otros tipos de soporte como el pergamino o la piel de las encuadernaciones (VALLS I SUBIRÁ, O. 1986:24).

$>$ En la restauración de libros y documentos se utilizan sustancias y materiales (papeles, adhesivos, colas, etc...) que pueden estar contaminados con conidios fúngicos o, en su caso, por esporas bacterianas.

$>$ Una de las causas más importantes de infección en bibliotecas y archivos es el polvo. El polvo tiene una composición heterogénea y variable formada por partículas químicas, huevos de insectos, polen 


\section{Criterios \\ Principales características \\ de los hongos causantes \\ de alteraciones en \\ materiales celulósicos \\ M. Ángeles Calvo Torras \\ y otros}

de flores, conidios, esporas, etc... Se trata de un importante elemento dispersor de conidios y esporas fúngicas presentes en el ambiente y que circulan en el aire. Estos propágulos pueden situarse en las superficies de los materiales y desarrollarse cuando las condiciones son las adecuadas, dependiendo de la humedad relativa y de la temperatura.

$>$ La introducción de documentos infectados en archivos y bibliotecas también puede ser una fuente de infección. Para evitar este problema, se recomienda someter a los documentos de reciente adquisición o legado a un examen minucioso en un local completamente separado del resto, y a una exhaustiva limpieza y desinfección antes de incorporarlos al archivo.

$>$ Una de las causas accidentales que con mayor frecuencia motivan la aparición de hongos son las inundaciones. Éstas pueden ser provocadas por roturas de tuberías, grietas en muros, extinciones de incendios, goteras, etc. Estas catástrofes pueden llegar a crear unas condiciones favorables para el desarrollo de los microorganismos, como es la aportación de humedad al papel, que ayuda a provocar una rápida proliferación de los hongos.

\section{Factores que favorecen su desarrollo}

Exiten dos conjuntos de factores importantes para el crecimiento y la supervivencia de los hongos: las condiciones ambientales adecuadas y la presencia de determinados nutrientes.

\section{Factores ambientales}

Los hongos son microorganismos que necesitan de una temperatura y una humedad relativa adecuadas para desarrollarse. Si además añadimos falta de ventilación en el depósito y ausencia de luz en el lugar donde se encuentran los libros, las condiciones se convierten en ideales para la infección fúngica.

$>$ Humedad. Los hongos necesitan de la humedad para subsistir, y para esto dispone de dos fuentes: el aire y el propio objeto. Una de las fuentes de humedad es el aire que envuelve al sustrato celulósico, es decir, la humedad relativa. Generalmente, los hongos, para poder reproducirse, necesitan de una HR del aire entre 65-100\% (dependiendo de la especie). Según F. Gallo, las condiciones favorables para el desarrollo de los hongos son las siguientes (GIOVANNINI, A. 1999:192):

\begin{tabular}{lll|} 
Tabla 1 & & \\
Temperatura & & H.R.\% \\
Óptima & $24^{\circ} \mathrm{C}-35^{\circ} \mathrm{C}$ & $65 \%-100 \%$ \\
Mínima & $-7^{\circ} \mathrm{C}$ & $50 \%$ \\
Máxima & $50^{\circ} \mathrm{C}$ & \\
\hline
\end{tabular}

Tabla 2. Tabla de hongos

Fausta Gallo realizó una tabla de materiales dañados por los 8 hongos más frecuentes en archivos y bibliotecas. (GALLO, F. 1985 :131)

Otra de las fuentes es la humedad del aire que el propio objeto contiene. La naturaleza higroscópica del soporte celulósico afecta de una manera positiva al crecimiento de los hongos. El papel, al tratarse de un material higroscópico, puede retener suficiente agua y, en consecuencia, puede permitir el crecimiento de los hongos aunque las condiciones ambientales no sean las propicias para este desarrollo.

$>$ Temperatura. Los microorganismos generalmente necesitan para su subsistencia de una temperatura entre 15 y $35^{\circ} \mathrm{C}$. Dentro de esta diferencia de temperaturas, existen especies que son capaces de subsistir casi en el nivel de congelación $\left(0^{\circ} \mathrm{C}\right)$. Los hongos a bajas temperaturas paralizan su metabolismo y su desarrollo, permaneciendo latentes hasta que las condiciones medioambientales vuelven a ser las adecuadas para su crecimiento. Si se disminuye la temperatura, es imprescindible que la HR también disminuya, ya que en caso contrario podría provocarse una rápida infección. Sin embargo, también puede llegar a aparecer un brote fúngico a una temperatura superior de $62^{\circ} \mathrm{C}$. Con un aumento de temperatura, los microorganismos pueden desarrollarse a una HR más reducida. Así, por ejemplo, las cepas de Aspergillus flavus precisan una HR de 95\% a una temperatura de $12^{\circ} \mathrm{C}$ y, a $30^{\circ} \mathrm{C}$, sólo necesitan una HR de $81 \%$ (GIOVANNINI, A. 1999:192). Como hemos podido constatar, la HR y la temperatura son dos parámetros que van muy relacionados.

$>$ Ventilación. Cuando una biblioteca o un archivo están bien aireados, la humedad del propio objeto disminuye, e incluso desaparece, y la temperatura superficial del soporte disminuye. Como consecuencia, se modifican dos factores muy importantes en la formación de los hongos. El movimiento de aire posee una doble acción benéfica contra la aparición de los microorganismos. Por un lado, dificulta el desarrollo de las esporas y conidios (siempre dispersos en el aire), ya que impide que éstos, junto al polvo y otros elementos, se depositen en la superficie de los libros y además evita la formación de microclimas en los archivos en los que la temperatura y la HR son más altas que la existente en el medio ambiente circundante (el resto del depósito), como por ejemplo los espacios existentes entre los libros y la pared o la estantería. Además de la ventilación, la utilización de estanterías abiertas, que permiten la circulación del aire entre los libros y evitan así su estancamiento, también colaboran en evitar los microclimas.

$>$ Luz. Los hongos pueden desarrollarse con o sin luz, aunque las condiciones con poca iluminación favorecen su crecimiento. Para la gran mayoría de los hongos, al carecer de clorofila, la luz no es necesaria en su desarrollo, y por tanto pueden subsistir sin su presencia.

\section{Factores nutricionales}

Entre los nutrientes necesarios para la subsistencia de los microorganismos, podemos destacar en primer lugar la celulosa, contenida en las fibras del papel, diversas sustancias que intervienen en la manufactura del papel, el polvo, y elementos minerales y orgánicos. 


$\begin{array}{lccccccccc}\text { Géneros fúngicos } & \text { Papel Cartón } & \text { Cuero } & \text { Pergamino } & \text { Tinta } & \text { Colas } & \text { Sintéticos } & \text { Tejidos } & \text { Sellos cera } & \text { Fotografías Cintas magnéticas } \\ \text { Aspergillus } & X & X & X & X & X & X & X & X & X \\ \text { Penicillium } & X & X & X & X & X & X & X & X & X \\ \text { Chaetomium } & X & X & X & & & X & X & X & X \\ \text { Alternaria } & X & X & X & & X & X & X & X & X \\ \text { Fusarium } & X & X & X & & X & X & X & X & X \\ \text { Trichoderma } & X & X & X & & & X & X & X \\ \text { Cladosporium } & X & X & X & & X & X & X & X \\ \text { Rhizopus } & X & X & X & & & & X & X\end{array}$

> La celulosa contenida en el papel es el principal elemento nutricional de los hongos, aunque también pueden alimentarse de otros materiales constitutivos del papel y sustancias empleadas en encuadernación y restauración como aditivos, aprestos hechos con gelatina y almidón, estucados, colas orgánicas vegetales (engrudo) y animales (cola de nervios y huesos), las tapas de los libros, las gomas realizadas con resinas, etc.

$>$ Otro importante elemento nutricional de los hongos es el polvo, que por su composición heterogénea y variable (partículas químicas, huevos de insectos, polen de flores, conidios y esporas de microorganismos, etc.), aporta al microorganismo agua, puesto que retiene la humedad, factor imprescindible para el desarrollo fúngico. El polvo, además de agua, también posee elementos químicos y biológicos, que aportan a los hongos las sales y las materias orgánicas necesarias para su crecimiento: carbono, hidrógeno, oxigeno, nitrógeno, azufre, potasio, magnesio y fósforo.

> Se ha observado que existe otro factor que favorece el desarrollo de los microorganismos. Se trata del grado de acidez que se detecta en los papeles atacados por hongos. El pH óptimo para el crecimiento de los hongos celulolíticos suele estar entre 4 y 6 , por esta razón es importante que el papel posea una reserva alcalina y no sea ácido. Los hongos prefieren los medios ácidos (factor muy común en la mayoría de los papeles antiguos) para desarrollarse.

\section{Alteraciones que provocan en el soporte}

Cuando los hongos se establecen sobre un papel, se inician una serie de etapas en las que los microorganismos degradan el soporte celulósico. Esta serie de fases empiezan con la constatación de unas simples manchas de humedad en el papel. Posteriormente las hifas de los hongos empiezan a penetrar en las fibras celulósicas y, finalmente, llega a producirse la desintegración total o parcial de las fibras, a causa de la acción agresiva fúngica. Los daños ocasionados por una infección fúngica son casi siempre irreversibles y sólo se puede conseguir detener su acción y paliar algunos de sus efectos. Los hongos producen tres tipos de alteraciones en los soportes celulósicos: químicos, mecánicos y cromáticos.

\section{Alteraciones químicas}

Los microorganismos liberan unas sustancias capaces de alterar químicamente la celulosa, transformándola y degradándola, modificando de esta manera las propiedades del papel. Entre estas sustancias podemos destacar enzimas glucosídicos y ácidos orgánicos.

$>$ Los hongos celulósicos, mediante enzimas glucosídicos, destruyen los puentes de oxigeno que unen las moléculas que forman la cadena de celulosa llegando a formar celobiosa (polisa- cárido formado por dos moléculas de glucosa). Este compuesto es degradado, a su vez, por otros enzimas glucosídicos que separan las moléculas de glucosas consiguiendo así el principal nutriente de los hongos.

> Durante el metabolismo fúngico se degradan los nutrientes necesarios, dando lugar a la formación de ácidos orgánicos (oxálico, cítrico, succínico, fumárico, acético y láctico) que se depositan sobre el soporte. Estos ácidos provocan daños químicos en el soporte, debilitándolo, ocasionando un descenso del pH del papel y, a la vez, ayudan a un ataque secundario por parte de otros hongos.

\section{Alteraciones mecánicas}

Estas alteraciones se producen en el papel cuando los micelios de los hongos se introducen entre las fibras celulósicas. El micelio del hongo puede llegar a expandirse por el soporte celulósico hasta destruirlo en su totalidad, rompiendo todas las fibras. El resultado es un papel frágil, debilitado y de aspecto algodonoso.

Las especies implicadas principalmente en modificar las propiedades mecánicas del papel, pertenecen a los géneros Chaetomium, Trichoderma y Stachybotrys (CANEVA, G; NUGARI, MP; SALVADORI, 0. 2000: 91).

\section{Alteraciones cromáticas}

La degradación más visible del papel atacado por hongos se constata por la formación de manchas de diversos colores (rojo, violeta, amarillo-marrón, negro, etc.) que pueden observarse en el soporte. Una alteración cromática particular es el llamado Foxing, que tiene como característica la formación de manchas rojizas y oscuras, de dimensiones variables, que se desarrollan en ciertos papeles de una forma muy localizada.

El color de las manchas en el soporte celulósico provocadas por microorganismos no permite identificar qué tipo de hongo lo provoca. Esto es debido a que el pigmento de cada especie fúngica toma una coloración y una intensidad diferente dependiendo de las particularidades del papel que alteren. Entre las propiedades del soporte celulósico que intervienen en las distintas tonalidades está el pH, las presencia de colas (almidón o gelatinas), existencia de metales, etc. Asimismo influye, el tiempo de persistencia de la infección fúngica y la coexistencia de varios microorganismos (GALLO, F. 1985: 134)

El proceso que provoca dichas alteraciones cromáticas se relaciona con la presencia de hongos con micelio pigmentado y con la liberación de pigmentos sobre el sustratos, fundamentalmente (CANEVA, G; NUGARI, M.P; SALVADORI, O. 2000:91).

$>$ La liberación de pigmentos sobre el sustrato. Las manchas producidas por microorganismos son el resultado del metabolismo de los hongos. Se producen cuando los hongos metabolizan los nu- 


\section{Criterios}

Principales características de los hongos causantes de alteraciones en materiales celulósicos

\section{M. Ángeles Calvo Torras y otros}

trientes presentes en el substrato y segregan productos residuales pigmentados. Entre ellos, están los enzimas (celulasas o diferentes tipos de proteasas) y ácidos orgánicos (oxálico, fumárico, acético, láctico, glucónico, glucurónico, etc.), los cuales se depositan sobre el papel modificando sus propiedades químicas y deteriorándolo. Este tipo de manchas están formadas por un núcleo central oscuro y por una periferia de un color más claro. Estas pigmentaciones son muy dificiles de eliminar en las restauraciones, aunque en algunos casos pueden realizarse blanqueamientos puntuales.

> La existencia de hongos con micelio pigmentado. Los hongos se adhieren al sustrato con las hifas; éstas penetran entre las fibras del papel, produciendo unas manchas que origina su propia pigmentación. La coloración de los micelios no identifica a una especie de hongo en concreto, ya que depende de otros muchos factores.

> Características del papel. La coloración de las manchas producidas por los hongos también depende de las materias primas utilizadas en la manufactura del papel. Entre éstas encontramos impurezas metálicas de la pasta, aditivos como colas, almidón o gelatinas y fijadores, un $\mathrm{pH}$ de la pasta entre 4,8-5,6 (pH óptimo para el desarrollo fúngico) (VALLS I SUBIRÁ, O. 1986:148). Estas sustancias pueden haberse introducido en la pasta de papel en el momento de su fabricación o posteriormente, al realizarse un reapresto. Por otro lado, el proceso químico utilizado en la manufactura del papel y las condiciones medioambientales en las que se ha producido la infección pueden provocar ciertas pigmentaciones en el soporte celulósico.

\section{Hongos bibliófagos más destacados}

Los géneros de hongos más directamente implicados en la posible degradación del soporte celulósico y fundamentalmente del papel son: Rhizopus, Alternaria, Aspergillus, Penicillium, Cladosporium , Trichoderma, Fusarium y Chaetomium.

Entre ellos, los géneros Aspergillus, Penicillium y Chaetomium son los más frecuentemente aislados.

> Género Alternaria. Se incluye entre los Deuteromycetes u Hongos Imperfectos. Sus especies son capaces de degradar el papel y producir manchas de color pardo en el soporte. Este género daña los siguientes materiales: papel/cartón, pergamino, colas animales/vegetales, materiales sintéticos, tejidos, sellos de cera y cintas magnéticas. Dentro de este género existen muchas especies que destacan por atacar el papel como: A. tenuis, A. humicola, A. chartarum, entre otras.

$>$ Género Aspergillus. Se incluye entre los Deuteromycetes cuando se halla en fase Imperfecta y entre los Ascomycetes, si podemos detectar la formación de esporas. Es el más común y el responsable del $80 \%$ de las destrucciones de las encuadernaciones y de los daños ocasionados en archivos y bibliotecas. Puede provocar aci- dez y manchas de diferentes colores en el soporte. Estos microorganismos atacan y destruyen la celulosa, descomponiendo la fibra del papel en su totalidad. Su temperatura óptima de desarrollo es de $24-30^{\circ} \mathrm{C}$, la mínima $-10^{\circ} \mathrm{C}$ y la máxima $50^{\circ} \mathrm{C}$. La humedad relativa óptima es de 75-100\%, y la mínima de 50\% (VALENTÍN, N; GARCIA, R; DE LUIS, O; MAEKAWA, S. 1998:87). El género Aspergillus es capaz de dañar los materiales siguientes: papel/cartón, pergamino, tintas, colas animales/vegetales, materiales sintéticos, tejidos, sellos de cera, fotografías y cintas magnéticas. Las especies que destacan por atacar el papel son: A. fumigatus, A. sulphureus, A. niger, A. versicolor, A. flavus, entre otras.

> Género Cladosporium. Perteneciente a los Deuteromycetes, daña los materiales siguientes: papel/cartón, pergamino, materiales sitéticos, tejidos, sellos de cera y cintas magnéticas. Las especies de género son capaces de destruir las fibras del papel y provoca alteraciones cromáticas de color verde oscuro o negruzco, entre las que destaca $\mathrm{Cl}$. herbarum.

$>$ Género Chaetomium. Este hongo, productor de ascosporas, necesita bastante humedad para su crecimiento (70\%) y una temperatura de alrededor de $25-27^{\circ} \mathrm{C}$. Chaetomium es viable en sustratos fuertemente ácidos y provoca en el sustrato un valor $\mathrm{pH}$ ligeramente ácido entre 6 y $6,8 \mathrm{pH}$. Daña todos estos materiales: papel/cartón, pergamino, materiales sintéticos, tejidos, sellos de cera, fotografias y cintas magnéticas. Afecta más a la lignina de la madera que a la celulosa. Existen muchas especies que destacan por atacar el papel como: Ch. chartarum, Ch. murorum (ataca el papel de barba, periódico y de Manila) (KRAEMER KOELLER, G. 1973:318), Ch. kunzeanum, etc., produciendo acidificación y manchas color crema y rosa.

$>$ Género Fusarium. Este hongo Deuteromycete daña todos estos materiales: papel/cartón, pergamino, colas animales/vegetales, materiales sintéticos, tejidos, sellos de cera y fotografías. Como especie destacada encontramos a F. oxysporum.

$>$ Género Penicillium. Este microorganismo incluido entre los Deuteromycetes se desarrolla en ambientes con baja humedad (50-55\% $\mathrm{HR})$ y bajas temperaturas $\left(15-30^{\circ} \mathrm{C}\right)$ y su infección, como AspergiIlus, se elimina con el uso de germicidas. Su capacidad enzimática puede ser inferior que el Aspergillus, aunque degrada las fibras; provoca acidez y manchas verdes en el soporte. Entre las especies más destacadas por atacar el papel encontramos: P. notatum, P. frequentans, P.vermiculatum, entre otras. El género Penicillium daña todos estos materiales: papel/cartón, pergamino, tintas, colas animales/vegetales, materiales sintéticos, tejidos, sellos de cera, fotografías y cintas magnéticas.

$>$ Género Rhizopus. Se incluye entre los Zygomycetes. La temperatura óptima de desarrollo oscila entre $20-30^{\circ} \mathrm{C}$, aunque también se desarrolla a temperaturas inferiores. Daña diversos materiales: papel/cartón, pergamino, tejidos y fotografías, produciendo manchas pardas y acidificación en el soporte. 
$>$ Género Trichoderma. Este hongo incluido entre los Deuteromycetes destruye las fibras del papel rápidamente y otras sustancias que se pueden encontrar en las bibliotecas como: cartón, pergamino, materiales sintéticos, tejidos, sellos de cera y fotografias, produciendo manchas de colores verde oscuro. Destaca por atacar el papel la especie Trichoderma viride.

\section{Bibliografía}

Biodeterioro

ALLSOPP, D; SEAL, K.J. Introduction to Biodeterioration. Londres: Edward Arnold, 1986

CANEVA, G; NUGARI, M.P; SALVADORI, O. La Biología en la restauración. Hondarribia: Nerea, S.A., 2000

FLIEDER, FRANCOISE Y C. CAPDEROU. Sauvegarde des collections du Patrimonie. La lutte contra les détériorations biologiques. Paris: CNRS, 1999

GALLO, F. Biological factors in deterioration of paper. Facteurs biologiques de deterioration du papier. Roma ICCROM: Sintesi Gráfica s.r.I., 1985, p. 129-143

KRAEMER KOELLER, G. Tratado de la previsión del papel y de la conservación de bibliotecas y archivos. Madrid: Servicio de publicaciones del Ministerio de Educación y Ciencia. Secretaría general técnica, 1973

VAILLANT, M; VALENTíN, N. Principios básicos de la conservación documental y causas de su deterioro. Madrid: Servicio de Publicaciones del Ministerio de Educación y Cultura, 1996

Conservación

BELLO URGELLES, C., BORRELL I CREHUET, A. Restauración de la obra gráfica. Metodología aplicada a la reintegración gráfico-pictórica. Barcelona: Balaam, 1995

CUNHA, G.D.M; CUNHA, D.G. Library and archives conservation: 1980s and beyond. Metuchen, N.J.: Scarecrow Press, 1983, vol.I.

CUNHA, G.M. Métodos de evaluación para determinar las necesidades de conservación en bibliotecas y archivos: un estudio del RAMP con recomendaciones prácticas. París: UNESCO, 1988

DUCHEIN, M; FLIEDER, F. Livres et documents d'archives: sauvegarde et conservation. París: UNESCO, 1983

GIOVANNINI, A. De tutela librorum. La conservation des livres et des documents d'archives. Ginebra: Les editions, IES, 1999

ROPERT, M. Planificación, equipo, y provisión de personal de un servicio de preservación y conservación de archivos: un estudio del RAMP con directrices. Paris: UNESCO, 1989

THOMSON, G. The Museum environement. Madrid: Akal, S.A., 1998

VALLS I SUBIRÁ, O. La Conservació del paper. Barcelona: Impremta Juvenil, S.A., 1986

\section{Hongos}

A.A.V.V. Patrimoine culturel et alterations biologiques. Actes des journées d'études de la SFIIC. Poitiers: SFIIC, 1988
A.A.V.V. CBS Course of Mycology. Institute of the Royal Netherlands, Academy of Sciences and Letter's, 1975

A.A.V.V. La conservación de los bienes culturales. Bélgica: UNESCO, 1969

ALEXOPOULOS, C.J; MIMS, C.W. Introducción a la Micología. Barcelona: Omega, S.A., 1985

BICCHIERI, M; PAPPALARDO, G; ROMANO, F.P; SEMENTILLI, F.M; ACUTIS, R. Characterization of Foxing Stains by Chemical and Spectrometric Methods. Restaurator, v. 22, 2001, p.1-19

CASE, C; FUNKE, B; TORTORA, G. Introducción a la Microbiologia. Zaragoza: Acribia, S.A., 1993, $3^{\text {a }}$ ed.

GALLO, F. Biological factors in deterioration of paper. Roma: ICCROM, 1985

GRAEME, S. Moisture, ventilation and mould growth. Preventive conservation practice, theory and research. Otawa: Ashok Roy and Perry Smith, 1994, p. 149-153

LINDBLOM PATKUS, B. Emergency salvage of moldy books and paper, Preservation of Library \& Archival Materials. Massachusetts: Northeast Document Conservation Center, 1999

MERRITT, J. Moho y enmohecimiento: prevención del crecimiento de microorganismos en las colecciones de los museos. NARA (National Archives and Records Administration), 1993. http://www.nara.gov/arch/techinfo/preserva/primer/ Pertenece al nIV de: Normas Básicas para preparación, gestión y respuesta ante desastres: materiales con soporte de pape

NITTÉRUS, M. Fungi in Archives and Libraries. Restaurator, v. 21, 2000, p. 25-40

PARKER, T. A. Estudio de un programa de lucha integrada cotra las plagas en los archivos y bibliotecas. Paris: UNESCO, 1988

VALENTíN, N; GARCIA, R; DE LUIS, 0; MAEKAWA, S. Microbial Control in Archives, Libraries and Museums by Ventilation Systms. Restaurator, v. 19, 1998, p. 85-107

WOOD LEE, M. Prevención y tratamiento del moho en las colecciones de bibliotecas, con particular referencia a las que padecen climas tropicales: un estudio del RAMP. París: UNESCO, 1988

Papel

LIÉNARDY, A; VAN DAMME, P. Folia. Manuel de conservation et de restauration du papier. Bruxelles: Institut royal du Patrimoine artistique, 1989

RODRÍGUEZ, M.D. Degradación, mediante envejecimiento acelerado, del papel soporte de realizaciones artísticas actuales (óleo y acrílico). Universidad del País Vasco, Tesis Doctoral, 1999

RODRÍGUEZ, M.D. El soporte de papel y sus técnicas. Degradación y conservación preventiva. Universidad del Pais Vasco, Tesis Doctoral, 1999

Restauración

CRESPO, C; VIÑAS, V. Preservación y restauración de documentos y libros en papel. París: UNESCO Estudios Ramp (PGI-84/WS/25), 1984

VALLS I SUBIRÁ, O. La Conservació del paper. Barcelona: Impremta Juvenil, S.A., 1986

VIÑAS, V; VIÑAS, R. Les techniques traditionnelles de restauration: une étude RAMP. Paris: UNESCO, 1992http://www.unesco.org/webworld/ramp/html/ r8817f/r8817f00.htm 